\title{
CORRECTIVE FEEDBACK AND WRITING ACCURACY OF STUDENTS ACROSS DIFFERENT LEVELS OF GRAMMATICAL SENSITIVITY
}

\author{
Ayu Rizki Septiana' \\ Gunadi Harry Sulistyo ${ }^{2}$ \\ A. Effendi Kadarisman ${ }^{3}$ \\ Graduate Program in English Language Teaching State University of Malang \\ ayurizki.septiana@gmail.com',gunadi.hs@gmail.com², effendi.kadarisman@gmail.com \\ First received: 8 March $2015 \quad$ Final proof received: 16 July 2016
}

\begin{abstract}
This study investigates whether indirect corrective feedback is effective on students' writing accuracy and whether there is any interaction between corrective feedback and students' levels of grammatical sensitivity. A quasi-factorial design was adopted for this research. The subjects of the study were fourth-semester students of English Department, at a State University in Malang, selected randomly. The experimental group was treated with indirect corrective feedback and the control group with direct corrective feedback. A parametric statistical test, ANCOVA, was used to test the hypotheses. The findings show that there was no statistical difference on writing accuracy between the experimental and control groups. Yet, among students with a high level of grammatical sensitivity, there was significant difference in writing accuracy between those given indirect and direct corrective feedback. Further, there was no interaction between corrective feedback on writing accuracy and students' levels of grammatical sensitivity. However, indirect corrective feedback improved students' writing accuracy better than direct corrective feedback.
\end{abstract}

Keywords: indirect corrective feedback, direct corrective feedback, grammatical sensitivity, writing accuracy

People usually have tendency to air their feeling, plans, intuition and views in communication with other people. In addition to speaking that is usually used to express the tendency, writing also becomes the means to transform the tendency into action. Writing not only explains our thoughts, feelings, plans and experiments but also makes us communicate with others and explain ourselves (Skehan, 1998). Writing itself in its practice usually involves some steps to be done. According to Harmer (2004), there is a wheel of writing process that includes planning, drafting, editing and writing the final version. The editing step, as a part of the writing process, is belief to be very important. Here, response to ideas, organization and style may be given in the form of feedback. Hyland (2003, p.77) states that the importance of feedback in the writing process is in the editing step. Moreover, Hyland and Hyland (cited in Muth'im (2003, p.29) point out that feedback now is important for both encouraging and consolidating learning in education. Siswanti (2013, p.7) believes that the learners who receive feedback from the teacher are usually more motivated to revise and improve the quality of their writing compared to those who do not receive feedback. However, the students usually prefer the teacher written feedback to peer or oral feedback (Srichanyachon, 2012, p. 8). They give high trust to the teacher feedback, but not the peer feedback.
Meanwhile, spoken feedback can be embarrassing when given openly.

As Hyland (2003, p. 17) points it out, providing feedback is one of the most important tasks of the teachers of writing. In addition, Ferris (2007, p. 165) states that writing instructors realize that providing feedback is most time-consuming and also challenging. Yet, the teacher as a writing instructor should consider the students' preference for the feedback given (Hyland, 2003, p. 179). One type of favorite feedback to be given to the students' writing according to Leki (cited in Hyland, 2003, p. 179) is feedback on grammar, while the most common written feedback to be given in the classroom setting is corrective feedback, in which the teacher gives visible marks on the students' errors (Beuningen, Jong, and Kuiken, 2008, p. 280).

Corrective feedback, as defined by Keh (cited in $\mathrm{Li} \& \mathrm{Li}, 2012$, p. 28), is the input given containing information for the revision. However, corrective feedback has become a debatable issues in Second Language Acquisition (SLA) for a long time. Research on corrective feedback showed that the effect of correction on students' errors are rather discouraging (Dulay, Blurt, Krashen, 1982, p. 35). Corrective feedback, both written and oral feedback, is an integral part of teaching (Ellis, 2009). Yet, it seems that the corrective feedback in writing has different effects from the corrective feedback in speaking. Moreover, in spoken corrective feedback 
given to errors in speaking, the teacher usually uses immediate correction feedback in which he/she directly corrects the students' errors. This is sometimes discouraging for the students (Ellis, 2009). Meanwhile in written corrective feedback, the delayed corrective feedback that is given after the students submit their draft can work effectively. The difference between immediate and delayed corrective feedback further brings different effects on the students' errors.

In speaking, the corrective feedback can be divided into six categories, namely explicit correction, clarification requests, metalinguistic information, elicitation, repetition and translation (Rezaei, Mozaffari, \& Hatef, 2011, p. 22). Meanwhile in writing, there are two kinds of corrective feedback, namely, direct corrective feedback and indirect corrective feedback. According to Beuningen et al (2008, p. 282), indirect corrective feedback only consists of indication of errors in the students' writing, while direct corrective feedback identifies both the errors and the target forms. Moreover, direct corrective feedback, according to Srichanyachon (2012, p. 10), is given to the students by explicitly writing the correct forms of the students' errors while indirect corrective feedback is given to students' drafts by giving underlines, circles, codes, and other means without giving the target or the correct forms of the errors. In addition, in written corrective feedback, which is given to the students' writing, there is some growing evidence that it can play important roles on the students' linguistic accuracy (Ellis, 2009).

In recent years, there are studies that focus on identifying the more helpful feedback between direct and indirect corrective feedback (Lu, 2010). Yet, the investigations into it (e.g. Chandler, 2003; Erel \& Bulut, 2007; Beuningen et al., 2008; Abedi,
Latifi, \& Moinzadeh, 2010; Lu, 2010) are still inconclusive. Beuningen et al. (2008) found that direct corrective feedback is more helpful and brings long-term effects on the students' writing accuracy. Moreover, Chandler (2003) also found that direct feedback is more effective than the indirect feedback. However, direct corrective feedback is usually preferable by students at the lower level of L2 proficiency because it clearly shows where the errors occur and how to correct them (Siswanti, 2013, pp. 10-11). Yet, other researchers found that indirect feedback is more helpful than the direct feedback (e.g. Erel \& Bulut, 2007; Abedi et al., 2010; and Lu, 2010). The studies that they conducted found out that students who got indirect corrective feedback performed better in their future writing than students who got direct corrective feedback. The study conducted by Erel \& Bulut (2007), for instance, found that the group that received indirect corrective feedback made fewer errors than the direct corrective feedback group in terms of the 18 error types. In addition, according to Siswanti (2013, p. 9), both teachers and students prefer to have indirect corrective feedback techniques in indicating and giving the clue of how to correct the errors in the writing drafts. All these studies show that there is no conclusive result, that is, which corrective mode is more helpful for the students. Therefore, there is a room open for further research to find out which corrective feedback is more helpful.

Erel \& Bulut (2007) categorized errors to into 18 types. To characterize the types, symbols were used to indicate the error type on students' writing when the teacher gives the indirect corrective feedback. After the symbols were used to indicate the errors, the students have to self-correct the errors. Table 1 shows these types of errors.

Table 1. Error Types and the Symbols

\begin{tabular}{ll}
\hline Error types & Symbols \\
\hline 1. Punctuation, & Pun \\
2. Capitalization & Cap \\
3. Spelling & Sp \\
4. Word formation & Wf \\
5. Singular/plural form & Sing/plural \\
6. Subject-verb agreement & $\mathrm{S} \neq \mathrm{V}$ \\
7. Tense & $\mathrm{T}$ \\
8. Missing & Missing article/missing verb \\
9. Article usage & Art. (article) \\
10. Connector & Con. (connector) \\
11. Preposition & Prep. (preposition) \\
12. Pronoun & Pron. (pronoun) \\
13. Possessive 's & Pos. (possessive 's) \\
14. Extra wording & [ ] extra wording \\
15. Inappropriate word & Inapp. (inappropriate) \\
16. Redundancy & Re. (Redundancy) \\
17. Unclear expression & ? (unclear) \\
18. Word order & Ordering \\
\hline
\end{tabular}


As Hyland (2003) states, writing is usually seen as a product that combines the writers' grammatical and lexical knowledge. Moreover, Hyland (2003) argues that writing is a means of reinforcement of grammar. Therefore, in order to have a good writing with high accuracy on grammar, the students should have sensitivity to grammar. According to Carroll (cited in Skehan, 1998 , p. 200), grammatical sensitivity is the ability to understand the contribution that words make in a sentence. Moreover, according to Carroll (cited in Krashen, 1981, p. 19), grammatical sensitivity is the individual ability in defining the syntactical pattern of a sentence. In relation to the error types proposed by Erel \& Bulut (2007), students who have good sensitivity in grammar tend to avoid making mistakes related to the syntactical pattern. Tokowicz \& MacWhinney (2005) define sensitivity in grammar refers more to the response of our brain when we see ungrammatical sentences rather than grammatical sentences. Therefore, when students can differentiate ungrammatical sentences from grammatical sentences, it can be said that they have good sensitivity to grammar.

Related to the grammatical sensitivity, different students are believed to have different levels of grammatical sensitivity (Kormos, 2012). To know the level of students' grammatical sensitivity, it is necessary to conduct an aptitude test such as "Modern Language Aptitude Test" (MLAT) or the "Language Aptitude Battery" (LAB) (Krashen, 1981). Usually, those at a high level of grammatical sensitivity will show a better improvement in writing accuracy than those at a low level of grammatical sensitivity. However, MLAT and $\mathrm{LAB}$ are not effective to test the students' levels of grammatical sensitivity since it is deployed to test not only the grammatical sensitivity but also the overall language aptitude such as phonetic coding ability, inductive ability and verbal intelligence. Moreover, Lightbown \& Spada (1990) argue that MLAT and LAB reveal the performance on any foreign language which is not specific to English as a foreign language. In line with this argument, MLAT and LAB are not effective to be utilized to test the students' levels of grammatical sensitivity since it is not only inaccurate for the purpose of the present study, but also uneconomical. There is a certain fee to be paid to get the MLAT. Further, the permission in using MLAT in classroom context is very difficult to get. Along with these arguments, another strategy is proposed for the purpose of the present study to adapt the 'Error Recognition' part in TOEFL to test the students' levels of grammatical sensitivity. Sulistyo (2001) states that error recognition in Grammar and Written Expression in TOEFL assesses more on grammatical sensitivity than communicativeness of the expressions.

This study, therefore, intended to find out the effects of the corrective feedback on the students' writing as seen from the perspective of students with different levels of grammatical sensitivity. This study intended to find out whether different levels of grammatical sensitivity make the effect of corrective feedback significantly different. In other words, this study tried to find out that one of the factors that influence the effectiveness of corrective feedback on the students' writing is the level of grammatical sensitivity.

Since grammatical sensitivity is one of the variables of interest in this research, there is a rationale of choosing this variable to be involved in the present study. Grammatical sensitivity is one of the language aptitudes that contribute to the learner differences (Krashen, 1981). Yet, there is not much research related to grammatical sensitivity that can be found in relation with corrective feedback. Piraud (2008) performed one of the few studies about grammatical sensitivity. In this research, the correlation between grammatical sensitivity, brain dominance, and EFL training to improve gains is exerted. Yet, the study of grammatical sensitivity and its relation to the students' writing is not revealed empirically yet.

The present study was interested in finding the relationship between corrective feedback and the students' levels of grammatical sensitivity since in Indonesia English is a foreign language that is learned by students from the elementary school to the university levels. Moreover, according to Lightbown \& Spada (1990), in L2 learning there is very little structural grading to grammar. Therefore, the students may lack mastery in grammar. In this line of argument, it is necessary to know the levels of grammatical sensitivity of the students. Different levels of grammatical sensitivity among students can affect their language learning (Krashen, 1981). Further, as related to the writing skill, the effect of students' levels of grammatical sensitivity on their writing ability is therefore worth investigating. More specifically, the present study aims at investigating whether indirect corrective feedback is instructionally effective in students' writing accuracy and whether there is any interaction between corrective feedback given to the students' writing across students' different levels of grammatical sensitivity.

On the basis of the background described previously, the present study scrutinizes the answers to questions expressed as follows:

(1) Was there any difference in the writing accuracy between the students treated with indirect corrective feedback and those treated with direct corrective feedback?

(2) Was there any difference in the writing accuracy between the students with the high level of grammatical sensitivity treated with indirect corrective feedback and those with the high level of 
grammatical sensitivity treated with direct corrective feedback?

(3) Was there any difference in the writing accuracy between the students with the low level of grammatical sensitivity treated with indirect corrective feedback and those with the low level of grammatical sensitivity treated with direct corrective feedback?

(4) Was there any interaction between corrective feedback treatments on the students' writing accuracy and the students' levels of grammatical sensitivity?

\section{METHOD}

This study intended to find out the effect of both indirect and direct corrective feedback on the students' writing accuracy as seen from their different levels of grammatical sensitivity. Due to inability to assign subjects to groups randomly, this research used a quasi-experimental design. However, in an experimental study, several independent variables are needed to provide a better explanation for the outcome. This present study puts the level of grammatical sensitivity as a variable that influences the method used to give feedback to the students' writing. Therefore, this research involved dependent and independent variables. The dependent variable of the research was the students' writing accuracy. Meanwhile, there were two independent variables, namely the method of giving written feedback and the students' level of grammatical sensitivity. The method of giving written feedback was further differentiated into indirect corrective feedback and direct corrective feedback, while the students' levels of grammatical sensitivity here were classified into two, namely high and low levels. Further, attribute variables were embedded into this research by assigning subjects to groups based on such existing variables. The independent variables of either type were known as factors. Therefore, quasi-experimental research, that is a factorial design, was used in this study since it was intended to determine whether the effects of different instructional methods were influenced by the language aptitudes of the learners. However, this study did not assume that one instructional method is better than another; nor did it assume that students with a certain level of grammatical sensitivity are better learners than others.
Factorial designs are used in the educational experiments when the researcher determines the effect of two or more independent variables on a dependent variable (Borg \& Gall, 1983, p. 685). The factorial design has several important strengths. First, it permits the simultaneous examination of more than one independent variable. This can be critical because most, if not all, human behavior is determined by more than one variable. Second, it allows us to test several hypotheses in a single research study. It can be more economical to use a factorial design than to conduct several individual studies, in terms of both the number of participants and the researcher effort. This research employed a simple factorial design that was $2 \times 2$, which was further read as 2 by 2 .

The population of this study was the fourth semester students who were officially registered at English Department State University of Malang. Two hundred and ten students became the accessible population of this research. Due to the large population and inability to assign subjects into the experimental and the control groups randomly, two existing classes out of ten classes that had been registered officially at the beginning of the semester were considered. Moreover, since the population of this research was naturally existent in groups, cluster random sampling was carried out to take samples of the research and determine two classes assigned as the experimental and the control groups. It is in line with Latief's suggestion (2011) that cluster random sampling can be used for randomly selecting the existing groups.

As has been stated before, the strategy of giving feedback on the students' writing implies in this research as the treatment was in the form of corrective feedback. In this case, the treatment of the experimental and the control groups was merely different in the form of corrective feedback given to the students' writing. The indirect corrective feedback was implemented in the experimental group and the direct corrective feedback was implemented in the control group. Before the treatments were carried out in the both groups, a pretest was conducted to know their initial ability in writing. For the treatment of giving the corrective feedback, each group experienced the methods in seven meetings. Finally, after having the same number of instructional meetings, both groups were given the posttest. Table 2 shows the different activities conducted with the experimental and the control groups.

Table 2 Teaching Procedures in Both Groups

\section{Experimental}

- The teacher gives a model text to the students and asks them to identify the text based on the structure of argumentative essay.

- The teacher shows the slide containing symbols of the errors that may be found in the students' writing.

\section{Control}

- The teacher gives a model text to the students and asks them to identify the text based on the structure of an argumentative essay.

- The teacher asks students to make an outline individually. 
- The teacher writes a sentence containing errors and gives the symbols of the errors.

- The teacher models how to correct the errors based on the symbol given.

- The teacher asks students to make an outline individually.

- The teacher asks them to write the outline including the thesis statement.

- The teacher asks students to share their thesis statement with the class to check whether it is effective or not.

- The teacher opens the discussion about the outline and the thesis statement.

- The teacher asks students to write a draft based on the outline they made at home.

- The teacher gives back the draft submitted by the students in the previous meeting.

- The teacher asks students to revise the draft based on the indirect corrective feedback given by the teacher.

- The teacher asks students to see the slide that shows the symbols of error. Students should self-correct their errors based on the symbols given.

- After finishing revising the draft, the teacher asks students to read the draft again.

- The teacher asks students to submit their final drafts.

There were two instruments used in this research: (a) pretest and posttest and (b) a grammatical sensitivity test. The first instrument, pretest and posttest of writing accuracy, is constructed to investigate the students' writing accuracy before and after the treatment. In this study, a scoring rubric was provided to score the students' writing accuracy. The final scores were recapitulated from the three raters who rated the students' writing accuracy in the pretest and the posttest. There were three components of writing accuracy to be rated, namely, grammar, vocabulary use, and mechanics. The second instrument, the test of students' levels of grammatical sensitivity, takes the form of error recognition of grammar and is aimed to classify the students' grammatical sensitivity levels into high and low levels. To be categorized into those who have high level of grammatical sensitivity, according to Piraud (2008), students should correctly answer $65 \%$ of 30 questions given. This test was constructed with the purpose to make it more appropriate with the 18
- The teacher asks them to write the outline including the thesis statement.

- The teacher asks students to share their thesis statement with the class to check whether it is effective or not.

- The teacher opens the discussion about the outline and the thesis statement.

- The teacher asks students to write a draft based on the outline they made at home.

- The teacher gives back the draft submitted by the students in the previous meeting.

- The teacher asks students to revise the draft based on the direct corrective feedback given by the teacher.

- The teacher asks the students to rewrite their essay in a new paper. Students can directly rewrite the draft since the feedback given has shown the correct forms of their errors.

- After finishing revising the draft, the teacher asks students to read the draft again.

- The teacher asks students to submit their final drafts. errors based on categorization of error by Erel \& Bulut (2007) to be identified in this present research. The grammatical sensitivity test was conducted for both the experimental and the control groups at the beginning of the treatment. The test was adapted from Barron's TOEFL 11th Edition by Sharpe (2004), especially the error recognition part. In this part, a sentence with particular grammatical complexities containing a grammatical mistake should be recognized by the test takers.

\section{RESULTS AND DISCUSSION}

The pretest results were in the form of scores of the writing accuracy obtained from the writing test that was administered to both the experimental and the control groups before the treatments began. The pretest mean score of the experimental group was 41.45 , while the pretest mean score of the control group was 41.85 . Here, the control group achieved .40 points higher than the experimental group. Meanwhile, the posttest results were obtained from 
the writing test that was administered to both the experimental and the control groups after the treatments were all performed. The mean score of the posttest of the experimental group was 46.02, while the mean score of the posttest of the control group was 44.79. The experimental group achieved 1.23 points higher than the control group. Table 3 shows the descriptive analysis of the pretest and the posttest for the experimental and the control groups.

Table 3. The Descriptive Statistic Analysis of the Pretest and the Posttest in the Experimental and the Control Groups

\begin{tabular}{lccc}
\hline \multirow{2}{*}{ Stages } & \multirow{2}{*}{ Descriptive Statistics } & \multicolumn{2}{c}{ Groups } \\
\cline { 3 - 4 } Pretest & Mean & Experimental & Control \\
& SD & 41.45 & 41.85 \\
& $\mathrm{~N}$ & 3.57 & 3.39 \\
\hline Posttest & Mean & 17 & 14 \\
& SD & 46.02 & 44.79 \\
& $\mathrm{~N}$ & 4.51 & 3.77 \\
\hline
\end{tabular}

The results of the grammatical sensitivity test for the experimental group categorized 9 students $(52.94 \%)$ into high level and 8 students $(47.06 \%)$ into low level of grammatical sensitivity. Meanwhile, results of the grammatical sensitivity test for the control group categorized 10 students (66.67\%) into a high level and 5 students (33.33\%) into a low level of grammatical sensitivity.

Furthermore, statistical assumptions were examined before deciding the appropriate statistical analysis as part of data analysis. If these assumptions were satisfactorily fulfilled, the parametric statistic was used to test the statistical hypotheses. If these assumptions were violated, then a non-parametric statistic was used to test the hypotheses (Peers, 1996). First, to estimate the normality of the data, a normality testing was computed and it was found that the significant values of the data of the experimental and the control groups were greater than the level of significance $\alpha=.05(\mathrm{Sig} .071>\mathrm{sig} .05)$ and ( Sig $1.000>$ sig .05). It means that the data were normally distributed. The second statistical assumption is the homogeneity. The homogeneity testing using SPSS v16 was performed and it was found that the significant value of the computation of Levene's test was .305. Since the significant value was greater than the level of significance (Sig $.305>$ sig .05), it means that the data were homogeneous. The last statistical assumption to be fulfilled is linearity. The data were linear if the significant value is greater than the level of significance. Based on the computation of linearity testing, it was found that the significant value was greater than the level of significance (Sig .422 > sig $.05)$. It means that the data were linear.

Based on examination on the fulfillment of those three statistical assumptions above, it can be concluded that all of the statistical assumptions were fulfilled. Therefore, a parametric test using ANCOVA was performed to test the hypotheses. Ross and Morisson (1996) stated that ANCOVA replicates ANOVA or MANOVA, but it employs an additional variable to control treatment group differences in aptitude and/or to reduce error variance in the dependent variable(s).

The first statistical computation using ANCOVA was performed to test the main hypothesis, yielding the result shown in Table 4.

Table 4. Summary of Analysis of Covariance for the Main Hypothesis

\begin{tabular}{lccccc}
\hline Source & Type III Sum of Squares & Df & Mean Square & F & Sig. \\
\hline Group & 17.137 & 1 & 17.137 & 1.326 & .259 \\
\hline
\end{tabular}

The result shows that $p$-value (.259) was greater than the level of significance $\alpha=.05$ ( $\mathrm{Sig}$ $.259>\operatorname{sig} .05)$. Therefore, it can be concluded that the students who were treated with indirect corrective feedback did not have significantly better writing accuracy than those who were treated with direct corrective feedback.

The second statistical computation using ANCOVA was performed to test the second hypothesis, yielding the result shown in Table 5 .

Table 5. Summary of Analysis of Covariance for Students with High Level of Grammatical Sensitivity

\begin{tabular}{lccccc}
\hline Source & Type III Sum of Squares & Df & Mean Square & F & Sig. \\
\hline Group & 32.520 & 1 & 32.520 & 6.189 & .024 \\
\hline
\end{tabular}

The result of the analysis of covariance from the students' writing accuracy of those who were at the high level of grammatical sensitivity is employed. The result shows that $p$-value (.023) was lower than the level of significance $\alpha=.05$ (Sig .024 $<\operatorname{sig} .05$ ). Therefore, it can be concluded that the students with the high level of grammatical sensitivity who were treated with indirect corrective 
feedback had significantly better writing accuracy than students with the high level of grammatical sensitivity who were treated with direct corrective feedback.
Third, the statistical computation of ANCOVA was also performed to test the third hypothesis, yielding the result shown in Table 6.

Table 6. Summary of Analysis of Covariance for Students with Low Level of Grammatical Sensitivity

\begin{tabular}{lccccc}
\hline Source & Type III Sum of Squares & Df & Mean Square & F & Sig. \\
\hline Group & 3.649 & 1 & 3.649 & .174 & .686 \\
\hline
\end{tabular}

The analysis of covariance from the students' writing of those who were at the low level of grammatical sensitivity is employed. The result shows that the $p$-value (.686) was greater than the level significance $\alpha=.05$ (Sig .686> sig .05). Therefore, it can be concluded that the students with the low level of grammatical sensitivity who were treated with indirect corrective feedback did not have significantly better writing accuracy than students with the low level of grammatical sensitivity who were treated with direct corrective feedback.

The last statistical computation of ANCOVA was performed to test the last hypothesis about the interaction between corrective feedback on writing accuracy and students' levels of grammatical sensitivity, yielding the result shown in Table 6 .

Table 7. Summary of Analysis of Covariance of Interaction between Corrective Feedback and the Students' Level of Grammatical Sensitivity

\begin{tabular}{lccccc}
\hline Source & Type III Sum of Squares & Df & Mean Square & F & Sig. \\
\hline Group & 9.043 & 1 & 9.043 & .819 & .374 \\
\hline
\end{tabular}

The result of the statistical computation shows that $p$-value (.374) was greater than level significance $\alpha=.05$ (Sig .374 > sig .05). Therefore, it can be concluded that there is no interaction between corrective feedback treated on the students' writing accuracy and the students' levels of grammatical sensitivity.

Based on the result of the hypothesis testing, it shows that the result of this research was in contrast with the result of previous research conducted by Chandler (2000) and Abedi et al. (2010), which revealed that indirect corrective feedback was effective on the students' writing. The result of this research revealed that indirect corrective feedback was not effective in improving the students' writing accuracy. A similar result was observed in Ferris \& Robert's (2001) study. Their study also revealed that there was no significant difference between the group that was treated with indirect corrective feedback and the group that was treated with direct corrective feedback. Although no significant difference was found, this research revealed that indirect and direct corrective feedback have improved the writing accuracy of the students. It can be seen from the improvement of the posttest score over the pretest score. This finding supports the findings of the research conducted by Erel \& Bulut (2007) and Lu (2010). Based on this finding, it can be concluded that the corrective feedback was actually beneficial to improve students' writing accuracy although the improvement was not significant. It is only a slight improvement that can be seen statistically. This possibly happened because the students had already got the effect of corrective feedback although it did not help them in an optimal way.
Furthermore, different from other studies which only see the effectiveness of corrective feedback on the students' writing accuracy, this study included grammatical sensitivity. When grammatical sensitivity was included as one factor that affects accuracy in the students' writing, it revealed that there was no interaction between corrective feedback and the students' levels of grammatical sensitivity. However, the result of statistical analysis showed that corrective feedback brought a statistically significant difference on the writing accuracy between students with a high level of grammatical sensitivity who were treated with indirect corrective feedback and students with a high level of grammatical sensitivity who were treated with direct corrective feedback. However, for the students with the low level of grammatical sensitivity, there was no statistically significant difference found on their writing accuracy between those who were treated with indirect corrective feedback and those who were treated with direct corrective feedback. Put another way, the low level of grammatical sensitivity did not contribute to accuracy of students' writing. Grammatical sensitivity, according to Piraud (2008), can be improved if there is proper training given to the students. Therefore, during this study, there might be some improvement on the students' level of grammatical sensitivity although there was no contribution that was found on the students' writing accuracy. In addition, based on the study conducted by Bueningen et al. (2008), the indirect corrective feedback was not effective in improving writing accuracy of the students who have low proficiency. This supports the finding of this study, in which the students with a low level of grammatical sensitivity 
in both groups did not show any significant difference in writing accuracy.

The acceptance of the null hypothesis $(\mathrm{Ho})$ in this study can be explained by considering some factors, such as the slight difference between the mean scores of the experimental and the control groups, the low level of grammatical sensitivity of the students in the experimental group, the method used for the control group, the number of meetings, and the guiding stage for the experimental group.

The first factor was the mean scores obtained in the posttest for both the experimental and the control groups. The mean score of the experimental group was 46.02 while the mean score of the control group was 44.79 . The mean difference between both groups was 1.23 . That slight difference means that there was no statistical difference on both groups although they were visually different in scores. Therefore, it was found that the students who were treated with indirect corrective feedback on their writing did not have significant difference in their writing accuracy than those who were treated with direct corrective feedback.

The second factor was the students with the low level of grammatical sensitivity in the experimental group. Based on the grammatical sensitivity test, it was found that there were more students with a low level of grammatical sensitivity in the experimental than in the control group. The students with the low level of grammatical sensitivity might not be helped by indirect corrective feedback since in the indirect corrective feedback the students were given only the symbols leading to self-correction. Carrol (cited in Krashen, 1981, p. 19) stated that the students with different levels of grammatical sensitivity might have differences in understanding the grammatical rules and applying them in creating new sentences. Therefore, when the students with a low level of grammatical sensitivity were given the indirect corrective feedback, it was found that they had difficulty transforming the indirect corrective feedback into acceptable grammar that would affect their writing accuracy. The various symbols in the indirect corrective feedback failed to lead them to use in their writings acceptable grammar, appropriate vocabularies, and correct mechanics.

The third factor that possibly caused ineffectiveness was the method used in the control group. The control group that was treated with direct corrective feedback easily transformed the feedback to their revision since they already got the correct forms of their errors. Ferris (2002) found that students who were treated with direct corrective feedback made fewer errors in their revision than students who were treated with indirect corrective feedback. Further, Beuningen et al. (2008) found that the students who were treated with direct corrective feedback could directly internalize the correct forms while the students who were treated with indirect corrective feedback were unable to do so. The students who were treated with indirect corrective feedback still needed to work on their own hypotheses about the correct form suggested by the symbols given. Therefore, it is reasonable that the students who were treated with direct corrective feedback did not have a significant difference in their writing accuracy from the students who were treated with indirect corrective feedback.

In this study, the students wrote three argumentative essays during the treatments and they were asked to revise each essay after it was given feedback. The students who were treated with direct corrective had been familiar with the errors and knew how to revise them into the correct forms. A study conducted by Beuningen et al. (2008) found that direct corrective feedback gives a long-term effect on the students' writing accuracy. Chandler (2003) also found that direct corrective feedback in the form of teachers' correction was the easiest way to help the students do their revision so that further in their own writing they can remember that they have to avoid making the same errors.

The fourth factor was the number of meeting sessions. In this study, the students in both groups had seven meetings of treatment. Seven meetings were conducted in less than a month, so that it is likely that the effect of indirect corrective feedback given to the students in the experimental group was not measurable. Chandler (2003) argued that writing quality is slow to show measurable effects. Further, Chandler (2003) who also did research on corrective feedback did the treatments for over ten weeks while Beuningen et al. (2008) did the treatment in one semester. Therefore, with such a short period of time for the treatments in this study, the effects of the indirect did not show any significant improvement yet on the students' writing accuracy.

The fifth factor that possibly caused ineffectiveness was the guiding stage for the experimental group. The experimental group was treated with indirect corrective, which was new to them. The students had not been familiar with the symbols given as the corrective feedback so that it was difficult for them to interpret the symbols. As a result, they did not show a significant improvement on their writing accuracy. Although in the first meeting of the treatments they got the modeling of how to revise the writing based on the indirect corrective feedback, some students, especially those at the low level of grammatical sensitivity, still had difficulties revising their writing. One meeting in modeling the revision based on the indirect corrective feedback was not enough so that the students did not comprehend well how to revise their writing. The other six meetings in which the students practiced revising their writing also did not cover their need in comprehending the feedback since they still needed the teacher's guidance more and more. 
Leaving the factors that possibly caused ineffectiveness of the indirect corrective feedbacks, this study revealed that both methods, indirect and direct corrective feedback, helped the students in improving the scores of their writing accuracy. The students in the experimental group who were treated with indirect corrective feedback had some improvement in their mean scores after being given the treatments. They were also trained to interpret the symbols given as the feedback to revise their writing. Thus, students who were treated with indirect corrective feedback obtained the ability of self-correcting based on the feedback given.

Next, the students who were treated with direct corrective feedback also got the benefit from the feedback given to their writing. Since the feedback given was in the correct forms of their errors, they could easily learn the acceptable grammar, the appropriate vocabulary, and the correct mechanics that should be used in their writing. They could take a look at their writing which has already been given the feedback and copy the correct forms to their revision. Further, the direct corrective feedback gave the students an experience of how the correct forms should be written in their revision.

Finally, the acceptance of the null hypotheses $(\mathrm{Ho})$ is possibly due to several reasons mentioned before. Although this research revealed that indirect corrective feedback is not effective in improving the accuracy of the students' writing, it is a better method to use to respond to students' writing than direct corrective feedback, as shown by the different achievement in which the experimental group had a higher mean score than the control group. Compared to the pretest score, the posttest score of the experimental group showed higher improvement than the posttest score of the control group. In line with the study by Beuningen et al. (2008), this research also revealed that the use of corrective feedback improves the students' writing accuracy.

\section{CONCLUSION}

In accordance with the research problem and the results of data analysis, it can be concluded that the students who were treated with indirect corrective feedback did not have better writing accuracy than the students who were treated with direct corrective feedback. Yet, the present research revealed that, for students with a high level of grammatical sensitivity, there was statistically significant difference in writing accuracy between those treated with indirect corrective feedback and those treated with direct corrective feedback. However, for students with a low level of grammatical sensitivity, there was no statistically significant difference in writing accuracy between those treated with indirect corrective feedback and those treated with direct corrective feedback. Further, it was also found that there was no interaction between corrective feedback and students' different levels of grammatical sensitivity; there was effect of the use of corrective feedback yet no interaction was found. Therefore, it can be concluded that the levels of grammatical sensitivity give no impact on students' writing accuracy after they are treated with corrective feedback.

The slight difference between the mean scores of the experimental group and the control group, the number of students who are at a low level of grammatical sensitivity, the method used for the control group, the number of meetings, and the guiding stage for the experimental group possibly cause the acceptance of the null hypotheses. However, the indirect corrective feedback is still a better method to respond to students' writing than the direct corrective feedback, as shown by the different mean scores of both groups. Further, compared to the pretest score, the posttest score of the experimental group that was treated with indirect corrective feedback showed higher improvement than the posttest score of the control group, which was treated with direct corrective feedback.

This research has its limitations. One of the limitations of this research is that the researcher carried out the treatment for the control group using the direct corrective feedback. As a result, this may be the cause of an experimenter effect threat. According to Borg \& Gall (1983), the researcher should not work directly with the control group to avoid the experimenter effect in which a bias between the treatment for the experimental group and the control may exist. In addition, the research implies that the methods used to respond to the students' writing also affect their writing accuracy. In this respect, the teacher should consider implementing a small conference to maximize the use of indirect corrective feedback. A small conference in which the students can ask for suggestions and further guidance from the teacher related to the symbols given as the feedback will make the students able to find the correct forms of the errors. This will help much especially the students at a low level of grammatical sensitivity.

Another weakness in this study is the short time of the treatment. While other studies related to the corrective feedback were carried out in more than twelve meetings, even in one whole semester, this study was carried out only for nine meetings. Since writing is difficult to learn, it is also difficult to see the progress of the students' writing after giving corrective feedback for the short time. As a result, there was no significant effect on their writing accuracy related to corrective feedback.

For other researchers who want to conduct further similar research in relation with the research findings in this research, the following suggestions are offered. First, it should be interesting to implement indirect corrective feedback with different text types and different research settings. 
Furthermore, it should also be interesting, to include content and organization of the students' writing. So, it is suggested that further research in corrective feedback investigate the effectiveness of corrective feedback in improving the accuracy, content, and organization of the students' writing. In addition, adding extra meetings during the guiding stage can help avoid misinterpreting the symbols for further use in revising the writing. The modeling of how to revise the errors based on the symbols given is also needed. This will decrease students' inability to transform the symbols for errors into the correct forms. Finally, it is also suggested that indirect corrective feedback be implemented in a longer period so that the students will become truly familiar with this new method of self-correcting in academic writing.

\section{REFERENCES}

Abedi, R., Latifi, M., \& Moinzadeh, A. (2010). The effect of error correction vs. error detection on Iranian pre-intermediate EFL learners' writing achievement. English Language Teaching, 3(4). Retrieved from ww.ccsenet.org/journal/index.php/elt/article/dow nload/6409/6178.

Beuningen, C.G.V., Jong, N.H. de., \& Kuiken, F. (2008). The effect of direct and indirect corrective feedback on L2 learners' written accuracy. International Journal of Applied Linguistics, 156(8), 279-296. Retrieved from http://dare.uva.nl/document/168926.

Borg, W.R. \& Gall, M.D. (1983). Educational research: An introduction. New York: Longman.

Chandler, J. (2000, March). The efficacy of error correction for improvement in the accuracy of L2 student writing. Paper presented at the AAAL conference.

Chandler, J. (2003). The efficacy of various kinds of error feedback for improvement in the accuracy and fluency of L2 student writing. Journal of Second Language Writing, 12(3), 267-296.

Dulay, H., Burt, M., \& Krashen, S. (1982). Language two. New York: Oxford University Press.

Ellis, R. (2009). Corrective feedback and teacher development. L2 Journal. 1(1), 3-18.

Erel, S.,\& Bulut, D. (2007). Error treatment in L2 Writing: A comparative study of direct and indirect coded feedback in Turkish EFL context. Journal of Social Sciences, 22(1), 397-415. Retrieved from http://sbe.erciyes.edu.tr/24$\% 20(397-415 . \% 20$ syf.

Ferris, D. (2002). Treatment of error in second language student writing. Ann Arbor: University of Michigan Press.

Ferris, D. (2007). Preparing teachers to respond to student writing. Journal of Second Language Writing, 16, 165-193
Ferris, D. R., \& Robert, B. (2001). Error feedback in L2 writing classes How explicit does it need to be? Journal of Second Language Writing. 10(3), 161-184.

Harmer. J. (2004). How to teach writing. London: Longman.

Hyland, K. (2003). Second language writing. Cambridge: Cambridge University Press.

Kormos, J. (2012). The role of individual differences in L2 writing. Journal of Second Language Writing, 2(3), 179-217.

Krashen, S.D. (1981). Second language acquisition and second language learning. Oxford: Pergamon.

Latief, M.A. (2011). Research methods on language learning: An introduction. Malang: UM Press.

Li, S. \& Li, P. (2012). Individual differences in written corrective feedback: A multi case study. English Language Teaching, 5(11), 38-44.

Lightbown, P. M. \& Spada, N. (1990). Focus-onform and corrective feedback in communicative language teaching. Studies in Second Language Acquisition, 12, pp 429-448. doi:10.1017/S0272263100009517.

Lu, Y. (2010). The value of direct and indirect written corrective feedback for intermediate ESL students. Unpublished Thesis. Auckland: Auckland University of Technology.

Muth'im, A. (2013). The effectiveness of indirect error correction feedback on the quality of university students' writing (Unpublished doctoral dissertation). State University of Malang, Malang, Indonesia.

Peers, I. (1996). Statistical analysis for education and psychology researcher. London: UK Falmer Press.

Piraud, M.O. (2008). Grammatical sensitivity: a correlational-explanatory study on brain dominance and EFL training to improve gains. Colombia Applied Linguistics Journal, 10, 93111.

Rezaei, S., Mozaffari, F., Hatef, A. (2011). Corrective feedback in SLA: Classroom practice and future directions. International Journal of English Linguistics. 1(11): 21-29.

Ross, S.M \& Morrison, G.R. (1996). Experimental research methods. Retrieved from www.aect.org/edtech/ed1/38.pdf.

Sharpe, P. J. (2004). How to prepare for the TOEFL test: Test of English as foreign language. (11th ed). Arizona: Barron's Educational Series Inc.

Siswanti, A. (2013). Providing coded feedback to improve the quality of students' writing at the Study Program of English of Universitas Brawijaya (Graduate Thesis, State University of Malang, Malang, Indonesia).

Skehan, P. (1998). A cognitive approach to language learning. Oxford: Oxford University Press. 
Srichanyachon, N. (2012). Teacher written feedback for L2 learners' writing development. Journal of Social Science, Humanities, and Arts, 12(1), 717.

Sulistyo, G.H. (2001). Technical considerations for taking the (paper-and-pencil-based) TOEFL.
TEFLIN Journal, 12(2), 223-241.

Tokowicz, N. \& MacWhinney, B. (2005). Implicit and explicit measures of sensitivity to violation in second language grammar. Studies in Second Language Acquisition, 27, 73- 204. 